Journal of Case Reports 2017;7(1):85-88

\title{
Stroke Due to Left Atrial Myxoma
}

\author{
PB TarunTeja, V Harshavardan ${ }^{1}$, Balajiramraj ${ }^{2}$ \\ Departments of ${ }^{1}$ Cardiothoracic Surgery and ${ }^{2}$ Community Medicine, SRM Medical University, Potheri, Tamil Nadu, India.
}

\section{Corresponding Author:}

Dr. PB TarunTeja

Email: tarunteja1994@gmail.com

This is an Open Access article distributed under the terms of the Creative Commons Attribution License (creativecommons.org/ licenses/by/3.0).

Received Accepted

Published

November 9, 2016

January 31,2017

March 5, 2017

\begin{abstract}
Background: Myxomas are commonest cardiac tumors mostly seen in left atrium. However, left atrial myxoma presenting with stroke is rare clinical condition whose etiology is unknown. Case Report: A 36-year-old female presented with left-sided hemiplegia for past 2 weeks along with headache for initial 2 days. She was diagnosed to be having stroke secondary to left atrial myxoma. Conclusion: The diagnosis of left atrial myxoma can be elusive, especially when the symptoms suggest a systemic illness. The significance of symptoms becomes apparent when the patient presents acutely with a motor deficit as a result of cerebrovascular embolism. We emphasize that patients with motor deficit should be carefully followed up for atrial myxoma.
\end{abstract}

Keywords: Embolism, Headache, Heart Neoplasms, Hemiplegia, Myxoma, Stroke.

\section{Introduction}

Cardiac myxoma is a source of emboli to the central nervous system and elsewhere in the vascular tree [1]. However, nonspecific systemic symptoms and minor embolic phenomena may be overlooked in the absence of any cardiac problems. In this situation, cardiac investigations may not be performed, and diagnosis of this rare condition may be delayed until the onset of more significant embolic disease, such as stroke with functional impairment, as in the case reported here. They usually present with reversible neurological events such as syncope, dizziness, headache [1]. The clinical presentation of cardiac myxoma is discussed, along with appropriate investigations and treatment, which may prevent such sequelae.

\section{Case Report}

A36-year-old female presented with left-sided hemiplegia for past two weeks and headache for initial two days. Two weeks back at about 2.30 pm while doing routine household work she had a sudden onset of headache. She developed inability to move left upper and lower limb simultaneously which was sudden in onset and non-progressive in nature. The patient was conscious however, no signs of cranial nerve disturbance were present. No significant history of any systemic disease or similar complaints in past was elicited. A general physical examination revealed conscious, oriented, alert and moderately built patient with temperature: $38^{\circ} \mathrm{C}$, pulse 88 per minute, respiratory rate 20 per minute, and blood pressure 134/83 $\mathrm{mmHg}$. Her central nervous system examination showed normal higher functions and cranial nerves. Motor system examination of left upper and lower limb were found to be hypertonic and power was $0 / 5$ in both left upper and lower limb, whereas the opposite limbs were normal. Sensory system examination was normal bilaterally. While performing superficial reflexes examination, plantar reflex showed dorsiflexion in left foot and abdominal reflex was absent on left side. All deep tendon reflexes were exaggerated on left side. Cardiovascular system showed mid diastolic murmur (MDM) in mitral area and was heard with the postural variation, where as respiratory system and abdomen examination were normal. 
CT brain showed non-hemorrhagic right cerebral acute infarct, left midline shift of $4.8 \mathrm{~mm}$ due to mass effect [Fig.1]. MRI brain showed chronic ischemic infarct with hemorrhagic transformation involving right fronto-temporal lobe, sub-acute infarct involving right ganglio capsular region. Multiple scattered area of blooming involving bilateral cerebral hemisphere suggestive of micro-bleeds were noted. Echocardiography showed dilated left atrium due to large left atrial mass measuring $2.5 \times 3.66 \mathrm{~cm}$. The mass was attached to inter-atrial septum and prolapsed into left ventricle during diastole [Fig.2]. Left ventricular ejection fraction was $68 \%$ with diastolic dysfunction.Trivial mitral regurgitation with absence of pulmonary hypertension or pulmonary edema was noted. CT chest showed mild cardiomegaly.

There was initial controversy in operating the left atrial myxoma as an emergency. Review of literature revealed that there are no strict guidelines regarding the management of acute stroke in case of left atrial myxoma. However those few cases which have been dealt with at centre's worldwide advised that it is better not to intervene in first 48 hours after stroke. It is safer to manage the acute cerebral infarct. In view of this, neurologist managed this patient with anti-edema measures like mannitol for a couple of weeks with a repeated CT scan to assess the cerebral infarct zone. In the third week CT brain revealed the normalization of midline shift, the patient was taken for open heart surgery (tumor excision with inter-atrial septum and repair with autologous graft). Median sternotomy was done, pericardium opened and patch harvested. Systemic heparinization $4 \mathrm{mg}$, aortabicaval cannulization, establishment of cardiopulmonary bypass along with cross clamping of aorta was done. Heart was arrested in diastole, right atrium opened and left atrium approached through fossa ovalis. The tumor was found to be attached to the inter-atrial septum covering the fossa ovalis. The entire mass was excised. After thorough wash, inter-atrial septal defect was repaired by using the pericardial patch

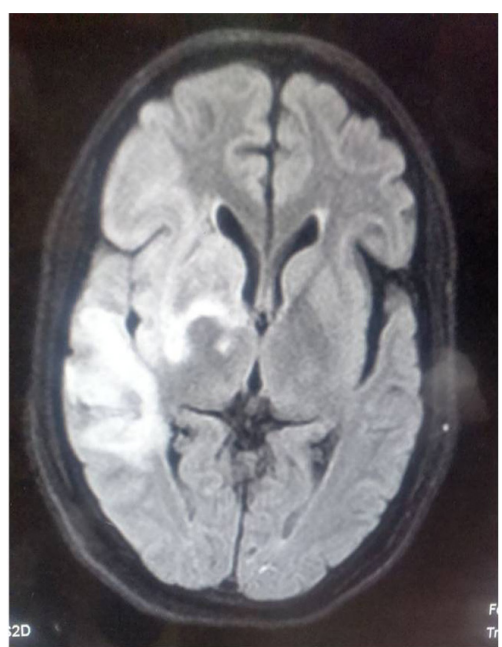

Fig.1: Cerebral infarct.

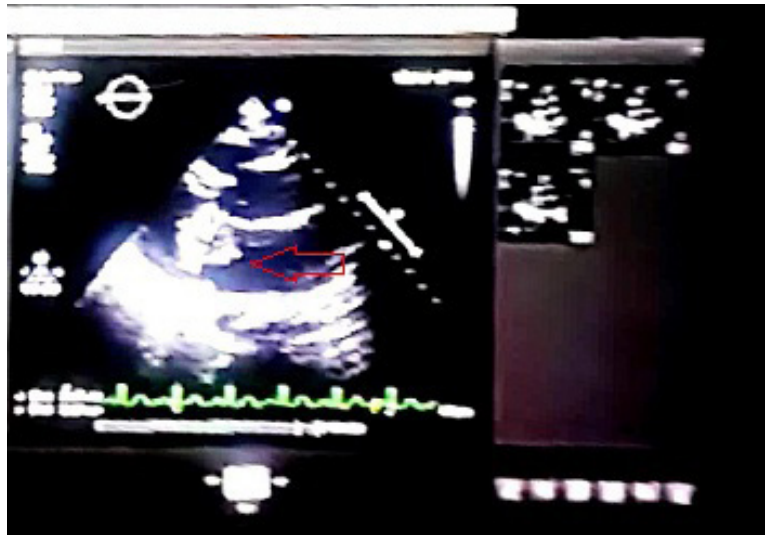

Fig.2: Myxoma attached to interatrial septum.

with 4.0 proline suture. Right atrium closure done, cross clamp released and heart picked up with sinus rhythm spontaneously. The patient was weaned from cardiopulmonary bypass, neutralized with protamine and decannulation, adequate hemostasis secured. Single mediastinal drain was kept and routine closure was done. Patient was shifted to intensive care unit in stable hemodynamics. Intraoperative myxoma tumor was noted to be very soft, friable, appeared like apple current jelly, attached to interatrial septum. Postoperative echocardiography showed normal left ventricular function, $63 \%$ ejection fraction, normal valves and chambers. The patient post-operative recovery was uneventful and vitals at present shows pulse 78 per minute, 
respiratory rate 18 per minute, and blood pressure $124 / 76 \mathrm{mmHg}$. She is able to walk independently without supports with hemiplegic gait.

\section{Discussion}

Young adults, female predominance, single cerebral vessel (mostly the middle cerebral artery) and multiple territory involvements and solitary left atrial myxoma epitomize the outstanding characteristics of the patients with cardiac myxoma stroke [2-4]. The most common affected cerebral vessel (the middle cerebral artery) and areas (the basal ganglion, cerebellum and parietal and temporal regions) correspond well to the common manifestations of conscious alteration, ataxia, hemiparesis and hemiplegia, aphasia and dysarthria. Initial CT scan carries a higher false negative rate in diagnosing cerebral infarction, and should be substituted by MRI, especially in patients with an immediate presentation. Echocardiography is a reliable means for determining the cardiogenic origin of stroke. Surgery is the main stay of the treatment.

The classic symptom triad of cardiac myxoma patients includes obstructive, embolic and constitutional manifestations [5]. Cardiac myxoma stroke is often of an acute onset, whereas tumor embolization including myxoma induced cerebral aneurysm and myxomatous metastasis may show a delayed presentation [6]. However, cardiac myxoma is responsible for only $0.5 \%$ of stroke, with females at the age of 50 years at greatest risk [6]. Embolic manifestations occur in $20-45 \%$ of patients with a cardiac myxoma, sometimes as the onset symptom [7], as a result of cerebral ischemia and less commonly hemorrhage [8]. In a series of 113 atrial myxoma patients with neurologic presentations, $83 \%$ presented with ischemic stroke, most often at multiple sites (41\%). Other manifestations included syncope (28\%), psychiatric symptoms (23\%), headache (15\%) and seizures (12\%) [9]. Alvarez-Sabín et al. [10] reported 11 of $28(39.3 \%)$ cardiac myxoma patients had embolic phenomena, which affected the cerebral arteries in $6(54.5 \%)$, peripheral arteries in two $(18.2 \%)$ and both cerebral and peripheral arteries in three $(27.3 \%)$ patients. Lee et al. [11] reported 13 of $59(22.0 \%)$ patients with a cardiac myxoma developed embolic events, $11(18.6 \%)$ of which were in the brain, Two (3.4\%) in the limb and one $(1.7 \%)$ in the eye. Furthermore, Yuan [12] reported a patient with a delayed cardiac myxoma resection developed multiple embolic events in the lower extremities. Bajraktari et al. [13] reported one cardiac myxoma patient who declined to all treatments for seven years eventually developed mesenteric embolism.

The size of the atrial myxoma is variable with a mean of 2.7 (range, 0.4-6.5) $\mathrm{cm}$ as reported by Lee et al. [2], and was $4.8 \pm 1.9 \mathrm{~cm}$ by Lee et al. [11]. Neurologic complications of atrial myxoma are most frequently cerebral infarcts caused by detached thrombus from the myxoma; while rarely by tumor fragments [2]. Active illness is often accompanied by elevation of erythrocyte sedimentation rate and C-reactive protein, hyperglobulinemia and anemia. Constitutional symptoms may be mediated by interleukin-6 produced by the myxoma itself [14]. MRI is more sensitive than CT in identifying subtle abnormalities of the brain [15]. Transthoracic and/or transesophageal echocardiography can be options for the screening of stroke of a cardiac source [16].

The timing of treatment in such patient is always a matter of intense debate. Soleimanpour et al. [17] proposed that the patients with a delayed presentation of more than 3-4.5 hours were not indicated for intravenous thrombolysis. Al-Said et al. [18] disagreed the use of recombinant tissue plasminogen activator for intravenous thrombolysis due to probable myxoma source infarct. Vogel et al. [19] suggested a 4-week delay of surgical resection of cardiac myxoma concerning the risk of intracerebral hemorrhage following cerebral infarction. Da Silva \& de Freitas [20] advocated a delayed surgery after a large stroke. However, 
Sethi [21] carried out emergent peripheral vascular and cardiac surgeries in a patient with an acute large infarct of a cardiac myxoma origin and the patient did well. Multicenter prospective studies on this particular patient population are anticipated in the future.

\section{Conclusion}

The diagnosis of left atrial myxoma can be elusive, especially when the symptoms suggest a systemic illness. In the case reported here, the significance of these symptoms became apparent when the patient presented acutely with a motor deficit as a result of cerebrovascular embolism. The presence of hemispheric infarction focused subsequent investigations on the possibility of a proximal source of embolization, which resulted in identification of the causative left atrial myxoma.

Contributors: PBTT: Case management, manuscript writing; VH: Surgical management, critical review of manuscript; BR: Manuscript editing and literature review. PBTT will act as guarantor. All authors approved the final version of the manuscript.

Funding: None; Competing interests: None stated.

\section{References}

1. Ekinci EI, Donnan GA. Neurological manifestations of cardiac myxoma: a review of the literature and report of cases. Intern Med J. 2004;34:243-249.

2. . Lee VH, Connolly HM, Brown RD Jr. Central nervous system manifestations of cardiac myxoma. Arch Neurol. 2007;64:1115-1120.

3. Ekinci EI, Donnan GA. Neurological manifestations of cardiac myxoma: a review of the literature and report of cases. Intern Med J. 2004;34:243-249.

4. Aziz F, Zaeem M. Atrial myxoma presenting as acute stroke: a case report and review of literature. Greener J Med Sci. 2013;3(5):171-173.

5. Alvarez-Sabín J, Lozano M, Sastre-Garriga J, Montoyo J, Murtra M, Abilleira S, et al. Transient ischaemic attack: a common initial manifestation of cardiac myxomas. Eur Neurol. 2001;45(3):165-170.

6. Browne WT, Wijdicks EF, Parisi JE, Viggiano RW. Fulminant brain necrosis from atrial myxoma showers. Stroke. 1993;24:1090-1092.

7. Ugurlu B, Oto Ö, Okutan H, Kutluk K, Silistreli E, Sariosmanoglu N, et al. Stroke and myxoma. Asian
Cardiovasc Thorac Ann. 2000;8:130-133.

8. Bienfait HP, Moll LC. Fatal cerebral embolism in a young patient with an occult left atrial myxoma. Clin Neurol Neurosurg. 2001;103:37-38.

9. Singh PK, Sureka RK, Sharma AK, Bhuyan S, Gupta V. Recurrent stroke in a case of left atrial myxoma masquerading vasculitis. J Assoc Physicians India. 2013;61:917-920.

10. Arruda MV, Braile DM, Joaquim MR, Soares MJ, Alves RH. Resection of left ventricular myxoma after embolic stroke. Rev Bras Cir Cardiovasc. 2008;23:578-580.

11. Lee SJ, Kim JH, Na CY, Oh SS. Eleven years' experience with Korean cardiac myxoma patients: focus on embolic complications. Cerebrovasc Dis. 2012;33:471-479.

12. Yuan SM. Prognostic prediction of troponins in cardiac myxoma: case study with literature review. Rev Bras Cir Cardiovasc. 2015;30:276-282.

13. Bajraktari G, Emini M, Berisha V, Gashi F, Beqiri A, Zahiti B, et al. Giant left atrial myxoma in an elderly patient: Natural history over a 7-year period. J Clin Ultrasound. 2006;34:461-463.

14. McCarthy PM, Piehler JM, Schaff HV, Pluth JR, Orszulak TA, Vidaillet HJ, Jr, et al. The significance of multiple, recurrent, and "complex" cardiac myxomas. J Thorac Cardiovasc Surg. 1986;91:389-396.

15. Morton-Bours EC, Jacobs MB, Albers GW. Clinical problem-solving. Eyes wide open. $\mathrm{N}$ Engl J Med. 2000;343:50-55.

16. Han E, Garrett A. Cerebrovascular accident caused by embolic atrial myxoma.Med Forum. 2013 14:Article 4. Available from: http://jdc.jefferson.edu/tmf/vol14/iss1/4 Accessed on November 9, 2016.

17. Soleimanpour H, Pashapour A, Mohammadi N, Golzari SE, Khodaverdizadeh $H$. Juvenile ischemic stroke secondary to cardiogenic embolism: a rare case report. Int J Prev Med. 2014;5(1):117-122.

18. Al-Said Y, Al-Rached H, Baeesa S, Kurdi K, Zabani I, Hassan A. Emergency excision of cardiac myxoma and endovascular coiling of intracranial aneurysm after cerebral infarction. Case Rep Neurol Med. 2013;2013:839270-839270.

19. Vogel B, Thomas D, Mereles D, Rottbauer W, Katus HA. Systemic embolization and myocardial infarction due to clinically unrecognized left atrial myxoma. Case Rep Med. 2011;2011:159024-159024.

20. Silva IR, de Freitas GR. Is it safe to proceed with thrombolytic therapy for acute ischemic stroke in a patient with cardiac myxoma? Case report and review of the literature. Eur Neurol. 2012;68(3):185-186.

21. Sethi NK. Is it safe to proceed with thrombolytic therapy for acute ischemic stroke in a patient with cardiac myxoma. Eur Neurol. 2013;69(2):67. 